\title{
Oral health attitudes and practices among college students in Jeju province
}

\author{
Ga-Hee Kim ${ }^{1}$, Hyeung-Keun Park², Se-Hoon Kahm³ ${ }^{3}$, Jae-Man Woo ${ }^{4,5}$, Chan-Woo Jo ${ }^{4,5}$, and Sung-Joon Kim²,6* \\ ${ }^{1}$ Research Assistant, Department of Public Health, Graduate School of Public Health and Welfare, Jeju National University, Jeju, Republic of Korea \\ ${ }^{2}$ Professor, Department of Public Health, Graduate School of Public Health and Welfare, Jeju National University, Jeju, Republic of Korea \\ ${ }^{3}$ Associate Professor, Department of Dentistry, Eunpyeong St. Mary's Hospital, The Catholic University of Korea, Seoul, Republic of Korea \\ ${ }^{4}$ Assistant Professor, Department of Public Health, Graduate School of Public Health and Welfare, Jeju National University, Jeju, Republic of Korea \\ ${ }^{5}$ Assistant Professor, Department of Dentistry, School of Medicine, Jeju National University, Jeju, Republic of Korea \\ ${ }^{6}$ Professor, Department of Dentistry, School of Medicine, Jeju National University, Jeju, Republic of Korea
}

\begin{abstract}
This study aimed to analyze the effects of oral healthcare awareness and related factors on the attitude toward oral health management and its practice among college students in Jeju province. A self-administered questionnaire survey was conducted on 365 students. The scores for the questions pertaining to the use of toothbrush three or more times a day, use of floss, and previous oral healthcare education $(p<0.05)$ were significantly higher in the oral healthcare students. The non-oral healthcare students presented with higher scores for the use of mouthwash $(p<0.05)$. Furthermore, the oral healthcare students presented with higher scores for both attitude and practice toward oral healthcare $(p<0.05)$ when compared with the non-oral healthcare students. The education level $(p<0.001)$ and gender $(p<0.001)$ were affected the attitude of the students toward oral healthcare, whereas only the sex $(p<0.05)$ had a significant effect on the practice of oral healthcare. The oral healthcare students (odds ratio $[\mathrm{OR}]=16.926)$ and 3rd-year students $(\mathrm{OR}=4.676$ ) demonstrated higher scores for "previous oral healthcare education" compared with the non-oral healthcare students and 1styear students, respectively. Use of dental floss increased with the advancement in the year of study (2nd year, OR=2.076; 3rd year, $\mathrm{OR}=2.424)$, and male students scored lower $(\mathrm{OR}=0.600)$ than the female students. Male students had lower scores $(\mathrm{OR}=0.489)$ for the question on regular dental visits. These findings indicate the need for specific educational tools and comprehensive research using standardized measures in future.
\end{abstract}

Key Words: Attitude, Oral heath, Practice, Students, Undergraduate

(c) This is an open-access article distributed under the terms of the Creative Commons Attribution Non-Commercial License (http://creativecommons.org/licenses/by-nc/4.0) which permits unrestricted noncommercial use, distribution, and reproduction in any medium, provided the original work is properly cited.

\section{서 론}

우리나라의 학교구강보건은 학령기의 구강건강 증진과 구강 보건지식과 태도 및 행동을 변화시켜 일생동안 구강건강을 관 리할 수 있는 능력을 배양하려는 체계적 교육행위를 말하는 것 이다. 하지만 학교구강보건사업의 대상은 초등학교 학생부터
중·고등학교의 학생들을 대상으로 하고 있으며 대학생은 성인 으로 분류하여 학교구강보건사업에 포함되어 있지 않다[1].

최근 우리나라의 대학 진학률은 2017년 76.9\%, 2018년 $77.2 \%, 2019$ 년 76.5\%로 높은 편이다[2]. 대학 진학률이 높은 만큼 대학생이라는 특수성을 가진 집단을 위한 건강 프로그램 의 개발·개설이 필요할 것으로 보인다. 대학생의 건강생활 실천

Received January 18, 2020; Revised February 17, 2020; Accepted February 17, 2020

${ }^{*}$ Corresponding author: Sung-Joon Kim, Department of Dentistry, School of Medicine, Jeju National University, 15 Aran 13-gil, Jeju 63241, Republic of Korea.

Tel: +82-64-717-1843, Fax: +82-64-717-1846, E-mail: samuelsj@jejunu.ac.kr

This article is the part of master's thesis by Ga-Hee Kim on the public health at Jeju National University in 2019.

Copyright $\odot$ 2020, Oral Biology Research Institute 
이 성인기의 의료비 절감효과 및 건강 투자 요소를 포함하고 있 기 때문에 미국의 경우, 주요 건강 관련요인 개선을 위한 프로그 램 제공에 관한 요구가 높아짐에 따라 대학교에서 학생 건강 프 로그램을 제공하고 있다. 그러나 국내 대학교에서는 학생 건강 프로그램이 개설이 미미한 실정이다[3].

2015년도 국민건강영양조사 결과에 따르면 영구치 우식 유 병률(만 19세 이상, 표준화)에서 $29.2 \%$ 였고, 연령별 유병률을 대학생 시기에 해당되는 19-29세 영구치 치아우식증 유병률은 $34.6 \%$ 로 나타났다. 치주질환 유병률(19세 이상, 표준화)의 경우 $26.4 \%$ 로 나타났으며 19-29세에서는 5.1\%의 유병률을 보였다. 이 수치는 14 년도에 조사된 4.3\%에서 증가된 수치로 치아우식 증과 치주질환 유병률의 경우 증가된 결과를 보이고 있는 것으 로 나타났다[4]. 2016년도 국민건강영양조사의 구강기능제한 율은 19-29세에서 9.7\%로 보고되었다[5]. 2017년도 국민건강 영양조사에서는 19-29세에서 9.0\%로, 16년도에 비해 17년도 에서 약간 낮아지긴 했으나 15 년도의 $6.6 \%$ 에 비해 증가했고, 저 작불편호소율의 경우 16년도에 19-29세에서 7.7\%로 보고되었 으며 17년도에 19-29세에서 7.8\%로 15년도의 6.4\%보다 높아 진 것으로 나타났다[6]. 이러한 결과를 보면 대학생들이 포함되 어 있는 대다수의 청년기 성인들에게서 구강질환 이환율이 증가 추세를 보이며 구강건강 실천율이 낮아진 것을 추정할 수 있다.

대학생 시기의 건강관리 습관은 장년기에 발생할 수 있는 각 종 구강 질병 예측요소라고 할 수 있으므로, 이 시기의 구강건 강관리와 관련된 다양한 정보습득과 실천은 건강한 노후생활 의 밑거름이 될 수 있다. 그러나 소홀히 관리될 경우, 대부분 학 령기에 발생된 치아우식증과 치주질환이 축적, 진행된다. 또한 대부분 대학생들은 자신의 구강건강상태에 대해 정확하게 알지 못하고 있으며 생활 기반 또한 조성되어 있지 않아 검진을 받는 비율이 낮은 실정을 보이고 있는데, 2017년 구강검진율은 19세 이상에서 35.4\%였으며 대학생 연령을 포함한 19-29세 사이에 서는 31.5\%였다[4]. 구강 질환으로 일상생활의 지장이나 결석 등 학업에 악영향을 받게 되면 학생 개인의 정신적, 육체적인 불 편, 고통과 더불어 사회적으로도 손실이라고 할 수 있다[3].

대학에서 전공은 특정한 분야에서 능력을 발휘하는 직업선택 에 있어서 중요한 부분이다. 또한 각 전공별로 교육과정이나 대 학환경, 특수성이나 전문성을 가지고 있으므로 이에 관한 구강 건강관련 요인들을 파악하고 이에 바람직한 구강건강관리 프로 그램을 고안하는 것이 바람직하다. 부산[7], 경남[8], 전라북도 전주시[9] 지역 대상의 기존의 연구 결과는 보건계열과 비보건 계열만으로 구분하여 구강보건계열과 일반보건계열에 구분을 두지 않거나 혹은, 구강보건계열과 비보건계열로 구분하여 일 반보건계열은 제외하고 진행되었다. 이러한 한계로 구강보건계 열과 일반보건계열 등 다양한 전공간의 차이를 확인하기에 어
려움이 있었다. 또한, 제주지역의 성인을 대상으로 하는 '제주지 역 성인들의 구강건강실태와 영향요인에 관한 연구' [10]나 ‘북 제주군 초등학교 학동들의 구강보건교육에 관련된 인식도 및 제1대구치 건강증진도 평가' [11], '제주도 고등학생의 구강건 강에 관한 인식 및 실태조사' [12]와 같이 성인이나 아동, 고등 학생들을 대상으로 하는 연구는 있었으나 대학생들을 대상으로 하는 연구는 부족했다. 이에 제주 지역의 대학생들을 대상으로 한 연구가 필요하다고 생각하였다.

본 연구는 제주도 내에 소재하는 대학교에 재학 중인 학생들 을 대상으로 전공에 따른 구강건강관리요인에 대한 인식도 및 인식도의 차이를 알아보고, 해당 구강건강관리요인들이 구강보 건태도, 실천 등에 어느 정도의 영향을 미치는지를 파악하여 적 절한 구강보건교육 필요성에 대한 분석 자료를 제시하고자 한다.

\section{대상 및 방법}

제주지역 구강보건계열(치기공과/치위생과), 일반보건계열 (간호학과/안경광학과), 비보건계열(관광경영과/호텔경영과/ 메카트로닉스과/호텔조리과)의 학과 학생 380명을 대상으로 2018년 12월에 설문조사를 실시하였다. 370명이 응답하였고, 불완전한 응답 5명을 제외한 365명(96.05\%)을 최종 연구 대상 으로 선정하였다. 설문지는 선행연구[3]에서 사용된 설문지를 실정에 맞게 수정·보완하여 총 52문항으로 작성하였다. 본 연구 는 2018년 11월 28일에 제주대학교 생명윤리심의위원회(Institutional Review Board)의 승인(JJNU-IRB-2018-052-001)을 받았다.

신뢰도 분석 결과, 구강보건지식·태도·실천의 Cronbach 알 파계수는 구강보건지식 0.530 , 구강보건태도 0.843 , 구강보건 실천 0.822였으며 Cronbach 알파계수 0.6을 기준으로 이보다 낮은 구강보건지식 항목은 분석에서 제외하였다.

수집된 자료는 SPSS Statistics ver. 22.0 (IBM Corp., Armonk, $\mathrm{NY}, \mathrm{USA}$ )을 이용하고 통계적 유의성 판정을 위한 유의 수준은 0.05 로 하였다. 대상자의 전공, 학년, 성별에 따른 일반 적 특성, 구강건강관리요인, 구강보건태도·실천은 일원배치분 산분석법(One-way ANOVA), 카이제곱 검증을 실시하였고, 구 강건강관리요인이 구강보건태도·실천에 미치는 영향은 다중회 귀분석을 실시하였으며, 구강건강관리요인에 영향을 미치는 일 반적 특성에 대한 로지스틱 회귀분석을 실시하였다. 
Table 1. Sociodemographic characteristics of respondents

\begin{tabular}{|c|c|}
\hline Category & Total $(n=365)$ \\
\hline \multicolumn{2}{|l|}{ Major } \\
\hline \multicolumn{2}{|l|}{ Department of Health } \\
\hline \multicolumn{2}{|l|}{ Oral Health } \\
\hline Dental Technology & $54(14.8)$ \\
\hline Dental Hygiene & $74(20.3)$ \\
\hline \multicolumn{2}{|l|}{ General Health } \\
\hline Nursing & $60(16.5)$ \\
\hline Ophthalmic Optics & $50(13.7)$ \\
\hline \multicolumn{2}{|l|}{ Non-Health Department } \\
\hline Tourism Management & $18(4.9)$ \\
\hline Hotel Management & $30(8.2)$ \\
\hline Hotel Culinary Arts & $49(13.4)$ \\
\hline Mechatronics & $30(8.2)$ \\
\hline \multicolumn{2}{|l|}{ Grade } \\
\hline 1 & $179(49.0)$ \\
\hline 2 & $88(24.1)$ \\
\hline 3 & $98(26.9)$ \\
\hline \multicolumn{2}{|l|}{ Sex } \\
\hline Male & $171(46.8)$ \\
\hline Female & $194(53.2)$ \\
\hline \multicolumn{2}{|l|}{ Age } \\
\hline Under 19 & $116(31.8)$ \\
\hline $20-29$ y & $234(64.1)$ \\
\hline 30 y or older & $15(4.1)$ \\
\hline \multicolumn{2}{|l|}{ Smoking } \\
\hline Yes & $83(22.7)$ \\
\hline No & $282(77.3)$ \\
\hline \multicolumn{2}{|l|}{ Drinking } \\
\hline Yes & $257(70.4)$ \\
\hline No & $108(29.6)$ \\
\hline
\end{tabular}

Values are presented as number (\%).

\section{결 과}

\section{대상자의 일반적 특성}

연구대상자의 일반적 특성과 분포는 Table 1 과 같다. 전공 은 각각 구강보건계열 128 명(치기공과 54 명 $14.8 \%$, 치위생과 74 명 $20.3 \%$ ), 일반보건계열 110 명(간호학과 60 명 $16.5 \%$, 안 경광학과 50 명 $13.7 \%$ ), 비보건계열 127 명(관광경영과 18 명 $4.9 \%$, 호텔경영과 30 명 $8.2 \%$, 호텔조리과 49 명 $13.4 \%$, 메카트 로닉스과 30명 8.2\%)이었다. 1학년 179명(49.0\%), 2학년 88명 (24.1\%), 3학년 98명(26.9\%)이었고, 남학생이 171명(46.8\%), 여학생이 194명(53.2\%)이었다. 만 19세 이하 116명(31.8\%), 만 20-29세 234명(64.1\%), 만 30세 이상은 15 명(4.1\%)이었다. 흡 연자는 83명(22.7\%), 비흡연자 282명(77.3\%)이었으며, 음주자 257 명(70.4\%), 비음주자 108명(29.6\%)이었다.

\section{전공 계열에 따른 구강건강관리요인}

연구 대상자 전공 계열에 따른 구강건강관리요인에 대한 결 과는 Table 2 와 같다. 일일 칫솔질 횟수의 분석 결과는 구강보건 계열에서 하루 2번 이하 칫솔질 한다는 경우가 3 명 $(2.3 \%)$, 하루 3 번 이상 125 명 $(97.7 \%)$ 이고, 일반보건계열에서는 하루 2 번 이 하가 9명(8.2\%), 하루 3번 이상이 101명(91.8\%)이었다. 비보건 계열에서 하루 2 번 이하가 17 명(13.4\%), 하루 3번 이상이 110 명(86.6\%)으로 나타났으며 통계적으로 유의한 분포의 차이가 있었다.

평균 칫솔질 시간의 분석 결과, 구강보건계열은 2 분 미만이 28 명(21.9\%), 2분 이상 4분 미만이 69명(53.9\%), 4분 이상이 31 명 $24.2 \%)$ 이었고, 일반보건계열은 2 분 미만이 31 명(28.2\%), 2 분 이상 4 분 미만이 43 명(39.1\%), 4분 이상이 36명(32.7\%)으 로 나타났다. 비보건계열은 2 분 미만 36 명(28.3\%), 2 분 이상 4 분 미만이 65명(51.2\%), 4 분 이상이 26명(20.5\%)으로 나타났 다. 통계적으로 유의한 분포의 차이가 없었다.

칫솔질 방법의 분석 결과, 구강보건계열에서 횡마법 3명 (2.3\%), 종마법 3명 $(2.3 \%)$, 치은마사지를 포함한 횡마법 4명 (3.2\%), 묘원법 40명(31.3\%), 회전법 78명(60.9\%)이었으며 일 반보건계열에서 치은마사지를 포함한 횡마법 6명(5.5\%), 묘원 법 39명(35.4\%), 회전법 52명(47.3\%)이었다. 비보건계열에서 횡마법 6명(4.7\%), 종마법 7명(5.5\%), 치은마사지를 포함한 횡 마법 9명(7.1\%), 묘원법 34명(26.8\%), 회전법 71명(55.9\%)으로 나타났다. 통계적으로 유의한 분포의 차이는 없었다.

구강관리용품 사용 여부 분석 결과, 치실을 사용한다는 응 답은 구강보건계열에서 50명(39.1\%), 일반보건계열에서 30명 (27.3\%), 비보건계열에서 24명(18.9\%)으로 응답되었으며, 통계 적으로 유의한 분포의 차이가 있었다. 혀클리너를 사용한다는 응답은 구강보건계열에서 28명(21.9\%), 일반보건계열에서 13 명(11.8\%), 비보건계열에서 21명(16.5\%)이었고, 통계적으로 유 의한 분포의 차이가 없었다. 치간칫솔 사용은 구강보건계열에 서 8명(6.2\%), 일반보건계열에서 15명(13.6\%), 비보건계열에서 13 명(10.2\%)이었고, 통계적으로 유의한 분포의 차이가 없었다. 구강세정제 사용은 구강보건계열에서 13 명(10.2\%), 일반보건 계열에서 26명(23.6\%)이었으며, 비보건계열에서 20명(15.7\%) 이었고, 통계적으로 유의한 분포의 차이가 있었다. 구강보건교 육경험을 한 경우는 구강보건계열에서 114 명(89.1\%), 일반보건 계열에서 12 명(10.9\%), 비보건계열에서 22명(17.3\%)이었고, 통 계적으로 유의한 분포의 차이가 있었다. 
Table 2. Oral health care factors according to major

\begin{tabular}{|c|c|c|c|c|c|c|}
\hline \multirow{2}{*}{\multicolumn{2}{|c|}{ Category }} & \multicolumn{3}{|c|}{ Major } & \multirow[b]{2}{*}{$\chi^{2}$} & \multirow[b]{2}{*}{$p$} \\
\hline & & $\begin{array}{l}\text { Oral Health } \\
\qquad(n=128)\end{array}$ & $\begin{array}{l}\text { General Health } \\
\quad(n=110)\end{array}$ & $\begin{array}{l}\text { Non-Health } \\
\quad(n=127)\end{array}$ & & \\
\hline \multicolumn{7}{|l|}{ Brushing frequency } \\
\hline \multicolumn{2}{|l|}{ Less than 2 times a day } & $3(2.3)$ & $9(8.2)$ & $17(13.4)$ & 10.639 & $0.005^{\dagger}$ \\
\hline \multicolumn{2}{|l|}{ More than 3 times a day } & $125(97.7)$ & $101(91.8)$ & $110(86.6)$ & & \\
\hline \multicolumn{7}{|l|}{ Brushing time } \\
\hline \multicolumn{2}{|l|}{ Less than 2 min } & $28(21.9)$ & $31(28.2)$ & $36(28.3)$ & 7.872 & 0.096 \\
\hline \multicolumn{2}{|c|}{ Less than 2 min and less than 4} & $69(53.9)$ & $43(39.1)$ & $65(51.2)$ & & \\
\hline \multicolumn{2}{|c|}{ More than 4 min } & $31(24.2)$ & $36(32.7)$ & $26(20.5)$ & & \\
\hline \multicolumn{7}{|l|}{ Brushing method } \\
\hline \multicolumn{2}{|l|}{ No answer } & $0(0.0)$ & $3(2.7)$ & $0(0.0)$ & 15.255 & 0.123 \\
\hline \multicolumn{2}{|l|}{ Scrub method } & $3(2.3)$ & $4(3.6)$ & $6(4.7)$ & & \\
\hline \multicolumn{2}{|c|}{ Vertical method } & $3(2.3)$ & $6(5.5)$ & $7(5.5)$ & & \\
\hline \multicolumn{2}{|c|}{ Scrub method including gingival massage } & $4(3.2)$ & $6(5.5)$ & $9(7.1)$ & & \\
\hline \multicolumn{2}{|c|}{ Circular method } & $40(31.3)$ & $39(35.4)$ & $34(26.8)$ & & \\
\hline \multicolumn{2}{|l|}{ Rolling method } & $78(60.9)$ & $52(47.3)$ & $71(55.9)$ & & \\
\hline \multicolumn{7}{|l|}{ Auxiliary oral care products } \\
\hline \multirow[t]{2}{*}{ Dental floss } & Use & $50(39.1)$ & $30(27.3)$ & $24(18.9)$ & 12.838 & $0.002^{\dagger}$ \\
\hline & Unused & $78(78.1)$ & $80(72.7)$ & $103(81.1)$ & & \\
\hline \multirow{2}{*}{ Tongue cleaner } & Use & $28(21.9)$ & $13(11.8)$ & $21(16.5)$ & 4.271 & 0.118 \\
\hline & Unused & $100(78.1)$ & $97(88.2)$ & $106(83.5)$ & & \\
\hline \multirow[t]{2}{*}{ Interdental toothbrush } & Use & $8(6.2)$ & $15(13.6)$ & $13(10.2)$ & 3.661 & 0.160 \\
\hline & Unused & $120(93.8)$ & $95(86.4)$ & $114(89.8)$ & & \\
\hline \multirow[t]{2}{*}{ Oral cleanser } & Use & $13(10.2)$ & $26(23.6)$ & $20(15.7)$ & 7.958 & $0.019^{*}$ \\
\hline & Unused & $115(89.8)$ & $84(76.4)$ & $107(84.3)$ & & \\
\hline \multicolumn{7}{|c|}{ Oral health education experience } \\
\hline \multicolumn{2}{|c|}{ Yes } & $114(89.1)$ & $12(10.9)$ & $22(17.3)$ & 193.476 & $<0.001^{\ddagger}$ \\
\hline \multicolumn{2}{|l|}{ No } & $14(10.9)$ & $98(89.1)$ & $105(82.7)$ & & \\
\hline \multicolumn{7}{|l|}{ Smoking } \\
\hline \multicolumn{2}{|l|}{ Yes } & $26(20.3)$ & $23(20.9)$ & $34(26.8)$ & 1.814 & 0.404 \\
\hline \multicolumn{2}{|l|}{ No } & $102(79.7)$ & 87 (79.1) & 93 (73.2) & & \\
\hline
\end{tabular}

Values are presented as number (\%).

${ }^{\star} p<0.05,{ }^{\dagger} p<0.01,{ }^{\ddagger} p<0.001$.

\section{구강보건태도와 실천}

연구 대상자 계열에 따른 구강보건태도와 실천에 대한 Likert 5점 척도의 결과는 Table 3과 같다. '칫솔질할 때 혀도 닦을 의 향이 있다.' 항목에서 구강보건계열 $4.62 \pm 0.603$, 일반보건계 열 $4.51 \pm 0.832$, 비보건계열 $4.20 \pm 0.827$ 이었고 구강보건계열 과 일반보건계열이 비보건계열보다 통계적으로 유의하게 높았 다. '저녁 식사 후와 자기 전 칫솔질을 할 의향이 있다.' 항목에 서 구강보건계열 $4.42 \pm 0.738$, 일반보건계열 $4.37 \pm 0.788$, 비 보건계열 $4.09 \pm 0.849$ 이었고, 구강보건계열과 일반보건계열 이 비보건계열보다 통계적으로 유의하게 높았다. '치약은 크림 상태로 사용할 의향이 있다.'에서 구강보건계열 $4.57 \pm 0.648$, 일반보건계열 $4.21 \pm 0.889$, 비보건계열 $3.93 \pm 0.901$ 이었고 구
강보건계열, 일반보건계열, 비보건계열 순으로 통계적으로 유의 하게 낮아졌다. '구강관리용품을 사용할 의향이 있다.'에서 구강 보건계열 $4.18 \pm 0.934$, 일반보건계열 $3.94 \pm 1.034$, 비보건계열 $3.71 \pm 1.009$ 이었고 구강보건계열이 비보건계열보다 통계적으로 유의하게 높았다. " 1 년에 한번 이상 스케일링을 받을 수 있다.' 항 목에서 구강보건계열 $4.44 \pm 0.729$, 일반보건계열 $3.97 \pm 1.096$, 비보건계열 $3.73 \pm 1.011$ 이었고 통계적으로 유의하게 낮아졌 다. 구강보건태도 문항 응답은 구강보건계열 $4.45 \pm 0.049$, 일반 보건계열 $4.20 \pm 0.068$, 비보건계열 $3.93 \pm 0.065$ 이었고, 통계 적으로 유의하게 낮아졌다.

'정기적인 구강검진을 받고 있다.' 항목에서 구강보건계열 $2.83 \pm 0.997$, 일반보건계열 $3.04 \pm 1.203$, 비보건계열 $2.89 \pm$ 1.135 이었으며, 통계적으로 유의한 차이는 없었다. '구강검진 후 
Table 3. Comparison of oral health attitude and practice according to major

\begin{tabular}{|c|c|c|c|c|c|}
\hline \multirow[b]{2}{*}{ Question } & \multicolumn{3}{|c|}{ Major } & \multirow[b]{2}{*}{$\mathbf{F}$} & \multirow[b]{2}{*}{$p$} \\
\hline & $\begin{array}{c}\text { Oral } \\
\text { Health }\end{array}$ & $\begin{array}{c}\text { General } \\
\text { Health }\end{array}$ & $\begin{array}{l}\text { Non- } \\
\text { Health }\end{array}$ & & \\
\hline \multicolumn{6}{|l|}{ Oral health attitude } \\
\hline 1. I am willing to brush my tongue when brushing. & $4.62 \pm 0.603^{\mathrm{a}}$ & $4.51 \pm 0.832^{\mathrm{a}}$ & $4.20 \pm 0.827$ & 10.496 & $<0.001^{\ddagger}$ \\
\hline 2. I am willing to brush my teeth after dinner and before going to bed. & $4.42 \pm 0.738^{\mathrm{a}}$ & $4.37 \pm 0.788^{\mathrm{a}}$ & $4.09 \pm 0.849$ & 6.221 & $0.002^{\dagger}$ \\
\hline 3. Toothpaste is intended to be used in a creamy state. & $4.57 \pm 0.648^{\mathrm{a}}$ & $4.21 \pm 0.889^{\mathrm{b}}$ & $3.93 \pm 0.901$ & 19.709 & $<0.001^{\ddagger}$ \\
\hline 4. Oral care products (dental floss, interdental toothbrush, etc.) are willing to use. & $4.18 \pm 0.934^{\mathrm{a}}$ & $3.94 \pm 1.034^{\mathrm{ab}}$ & $3.71 \pm 1.009^{\mathrm{b}}$ & 7.201 & $0.001^{\dagger}$ \\
\hline 5. I will take the scaling more than once a year. & $4.44 \pm 0.729^{\mathrm{a}}$ & $3.97 \pm 1.096^{\mathrm{b}}$ & $3.73 \pm 1.011$ & 18.080 & $<0.001^{\ddagger}$ \\
\hline Sub-total & $4.45 \pm 0.049^{\mathrm{a}}$ & $4.20 \pm 0.068^{\mathrm{b}}$ & $3.93 \pm 0.065$ & 18.798 & $<0.001^{\ddagger}$ \\
\hline \multicolumn{6}{|l|}{ Oral health practice } \\
\hline 1. I have regular oral examinations. & $2.83 \pm 0.997$ & $3.04 \pm 1.203$ & $2.89 \pm 1.135$ & 1.080 & 0.341 \\
\hline 2. If a dental treatment is required after a mouth exam, I will take the treatment. & $3.59 \pm 1.016$ & $3.54 \pm 1.202$ & $3.28 \pm 1.089$ & 2.889 & 0.057 \\
\hline 3. I brush my teeth after meals. & $3.96 \pm 0.873$ & $3.93 \pm 0.885$ & $3.76 \pm 0.906$ & 1.926 & 0.147 \\
\hline 4. I brush my teeth after a snack. & $2.96 \pm 1.015$ & $3.14 \pm 1.223$ & $2.95 \pm 1.053$ & 1.036 & 0.356 \\
\hline 5. I have been brushing before going to bed. & $4.13 \pm 0.896^{\mathrm{a}}$ & $3.94 \pm 1.069^{\mathrm{ab}}$ & $3.79 \pm 1.021^{\mathrm{b}}$ & 3.692 & $0.026^{*}$ \\
\hline 6. I avoid harmful foods to tooth. & $2.59 \pm 0.960$ & $2.64 \pm 1.123$ & $2.65 \pm 1.137$ & 0.136 & 0.873 \\
\hline 7. I have chosen toothbrush that is suitable for tooth and gum condition. & $3.33 \pm 0.932$ & $3.02 \pm 1.181$ & $3.17 \pm 1.077$ & 2.524 & 0.082 \\
\hline 8. I am using toothpaste that is suitable for tooth and gum condition. & $3.40 \pm 0.983$ & $3.10 \pm 1.117$ & $3.21 \pm 0.727$ & 2.638 & 0.073 \\
\hline Sub-total & $3.35 \pm 0.053$ & $3.29 \pm 0.074$ & $3.21 \pm 0.065$ & 1.248 & 0.288 \\
\hline
\end{tabular}

Values are presented as mean \pm standard deviation.

${ }^{\mathrm{a}, \mathrm{b}}$ Different letters represent significant different Duncan's multiple range test.

${ }^{*} p<0.05,{ }^{\dagger} p<0.01,{ }^{\ddagger} p<0.001$.

치과치료를 요하는 경우에는 치료를 받고 있다.' 항목에서는 구 강보건계열 $3.59 \pm 1.016$, 일반보건계열 $3.54 \pm 1.202$, 비보건 계열 $3.28 \pm 1.089$ 이었으며, 통계적으로 유의한 차이는 없었다.

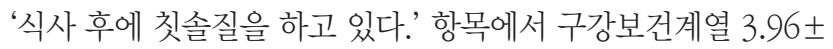
0.873 , 일반보건계열 $3.93 \pm 0.885$, 비보건계열 $3.76 \pm 0.906$ 이 었으며, 통계적으로 유의한 차이는 없었다. '간식 후에 칫솔질 을 하고 있다.' 항목 응답은 구강보건계열 $2.96 \pm 1.015$, 일반보 건계열 $3.14 \pm 1.223$, 비보건계열 $2.95 \pm 1.053$ 이었으며, 통계 적으로 유의한 차이는 없었다. '취침 전에 칫솔질을 하고 있다.' 항목에서 구강보건계열 $4.13 \pm 0.896$, 일반보건계열 $3.94 \pm$ 1.069 , 비보건계열 $3.79 \pm 1.021$ 이었고 구강보건계열이 비보 건계열보다 통계적으로 유의하게 높았다. '치아에 해로운 음식 을 피하고 있다.' 항목은 구강보건계열 $2.59 \pm 0.960$, 일반보건 계열 $2.64 \pm 1.123$, 비보건계열 $2.65 \pm 1.137$ 이었으며 통계적으 로 유의한 차이는 없었다. '치아와 잇몸상태에 적합한 칫솔을 선 택해서 사용하고 있다.' 항목에서 구강보건 계열 $3.33 \pm 0.932$, 일반보건계열 $3.02 \pm 1.181$, 비보건계열 $3.17 \pm 1.077$ 이었고 통 계적으로 유의한 차이는 없었다. '치아와 잇몸상태에 적합한 치 약을 선택해서 사용하고 있다.' 항목에서 구강보건계열 $3.40 \pm$ 0.983 , 일반보건계열 $3.10 \pm 1.117$, 비보건계열 $3.21 \pm 0.727$ 이 었으며 통계적으로 유의한 차이는 없었다. 구강보건실천의 평
균값은 구강보건계열이 $3.35 \pm 0.053$, 일반보건계열이 $3.29 \pm$ 0.074 , 비보건계열이 $3.21 \pm 0.065$ 이었고 통계적으로 유의한 차 이는 없었다. 구강보건태도, 실천 간의 상관관계는 0.433 ( $p<$ 0.01)으로 양의 상관관계가 있었다.

\section{구강건강관리요인이 구강보건태도·실천에 미치는 영향}

연구대상자의 일반적 특성과 구강건강관리요인이 구강보 건태도와 실천에 미치는 영향을 분석한 다중회귀분석결과는 Table 4와 같다. 먼저, 구강보건태도에 대한 구강보건계열의 비 표준화계수(B)는 0.457 , 보건계열의 $\mathrm{B}$ 는 0.223 으로 비보건계 열에 비해 구강보건계열과 일반보건계열이 통계적으로 유의하 게 높았다. 성별의 $\mathrm{B}$ 는 -0.327 로 여학생이 남학생보다 통계적 으로 유의하게 높은 것으로 확인되었다. 학년, 구강보건교육여 부, 아침식사횟수는 통계적으로 유의하지 않았다. 계열과 성별 이 구강보건태도에 영향을 미치고 있었으며 변수 간 상관관계 는 0.385 였고 $R^{2}$ 은 0.148 이었으며 Adjusted $R^{2}$ 은 0.132 로 설 명력은 $13.2 \%$ 로 나타났다. 구강보건실천에 미치는 영향에 대한 다중회귀분석 결과에서는 성별만이 구강보건실천에 영향을 미 치고 있었다. 
Table 4. Multiple regression analysis of oral health attitude and practice

\begin{tabular}{|c|c|c|c|c|c|c|}
\hline Category & & B & SE & $\beta$ & $\mathbf{t}$ & $p$ \\
\hline \multicolumn{7}{|l|}{ Oral health attitude } \\
\hline \multirow[t]{3}{*}{ Major } & Non-Health & Reference & & & & \\
\hline & General Health & 0.223 & 0.088 & 0.146 & 2.541 & $0.011^{\star}$ \\
\hline & Oral Health & 0.457 & 0.130 & 0.312 & 3.518 & $<0.001^{*}$ \\
\hline \multirow[t]{3}{*}{ Grade } & 1 & Reference & & & & \\
\hline & 2 & -0.099 & 0.086 & -0.061 & -1.159 & 0.247 \\
\hline & 3 & -0.112 & 0.121 & -0.071 & -0.930 & 0.353 \\
\hline \multirow[t]{2}{*}{ Sex } & Female & Reference & & & & \\
\hline & Male & -0.327 & 0.073 & -0.233 & -4.477 & $<0.001^{*}$ \\
\hline \multicolumn{2}{|l|}{ Oral health education experience } & -0.030 & 0.103 & -0.021 & -0.287 & 0.774 \\
\hline \multicolumn{2}{|l|}{ Breakfast } & -0.008 & 0.015 & -0.027 & -0.542 & 0.588 \\
\hline \multicolumn{7}{|c|}{$\mathrm{F}=8.874, p<0.001^{\ddagger}, \mathrm{R}=0.385, R^{2}=0.148$, Adjusted $R^{2}=0.132$, Durbin-Watson=2.036 } \\
\hline \multicolumn{7}{|l|}{ Oral health practice } \\
\hline \multirow[t]{3}{*}{ Major } & Non-Health & Reference & & & & \\
\hline & General Health & 0.057 & 0.094 & 0.038 & 0.613 & 0.540 \\
\hline & Oral Health & -0.086 & 0.139 & -0.059 & -0.622 & 0.534 \\
\hline \multirow[t]{3}{*}{ Grade } & 1 & Reference & & & & \\
\hline & 2 & -0.014 & 0.092 & -0.009 & -0.153 & 0.879 \\
\hline & 3 & 0.127 & 0.129 & 0.080 & 0.984 & 0.326 \\
\hline \multirow[t]{2}{*}{ Sex } & Female & Reference & & & & \\
\hline & Male & -0.154 & 0.078 & -0.110 & -1.971 & $0.049^{*}$ \\
\hline \multirow{2}{*}{\multicolumn{2}{|c|}{$\begin{array}{l}\text { Oral health education experience } \\
\text { Breakfast }\end{array}$}} & -0.125 & 0.111 & -0.087 & -1.126 & 0.261 \\
\hline & & -0.004 & 0.016 & -0.013 & -0.249 & 0.803 \\
\hline \multicolumn{7}{|c|}{$\mathrm{F}=1.616, p=0.129, \mathrm{R}=0.175, R^{2}=0.031$, Adjusted $R^{2}=0.012$, Durbin-Watson $=1.727$} \\
\hline
\end{tabular}

SE, standard error.

${ }^{*} p<0.05,{ }^{\dagger} p<0.01,{ }^{\ddagger} p<0.001$.

\section{구강건강관리요인에 영향을 미치는 일반적 특성에 대한 로 지스틱 회귀분석}

전공 계열, 학년, 성별을 독립변수로 하여 구강건강관리요인 에 대한 로지스틱 회귀분석 결과는 Table 5와 같다. 구강보건교 육 경험은 비보건계열을 기준으로 구강보건계열이 16.926배로 나타났고, 1학년 대비하여 3학년이 통계적으로 유의하게 4.676 배로 나타났다. 치실 사용을 종속변수로 한 분석결과는 비보건 계열을 기준으로 구강보건계열과 일반보건계열이 높았으나 통 계적으로 유의하지 않았다. 1학년을 기준으로 통계적으로 유의 하게 2학년이 2.076배, 3학년은 2.424배였다. 성별은 여학생에 비해 남학생이 0.600배로 낮았고 통계적으로 유의했다. 치과방 문 여부를 종속변수로 한 분석 결과, 보건계열을 기준으로 구강 보건계열, 일반보건계열이 높았고, 1학년을 기준으로 2학년, 3 학년이 높았으나 계열과 학년 모두에서 통계적으로 유의하지 않았다. 성별에서 여학생에 비해 남학생이 0.489 배로 낮았으며 통계적으로 유의한 것으로 나타났다.

\section{고 찰}

구강건강 수준은 구강건강에 관한 지식, 태도 및 행동을 합리 적으로 변화시킴으로써 향상되며 지식, 태도, 행동의 변화는 교 육을 통해서 변화된다[13]. 특히 구강보건교육은 과거 치료목적 의 인식 변화에 발맞추어 구강질환의 예방을 위해 모색된 다양 한 방법 중 적은 비용 대비 많은 효과를 가지고 있고, 주관적인 건강인식에 대한 관심이 높아지고 있는 시점에서 더욱 더 중요 하게 여겨지고 있다[14]. 본 연구는 제주도 내의 다양한 전공의 학생들을 대상으로 구강건강관리에 대한 인식도와 구강건강관 리요인들이 구강보건태도, 실천 등에 미치는 영향을 파악하여 적절한 구강보건교육에 대한 분석 자료로 활용하고자 실시하였 다. 표본 추출은 구강보건계열, 일반보건계열, 비보건계열 학과 가 모두 개설된 대학 1 개교로 선정하였다.

구강보건교육 경험은 비보건계열 대비 구강보건계열이 16.926 배 $(p<0.001)$ 경험한 것으로 나타났는데, $\mathrm{Kim}$ [15]이 치과계열 학생의 지식수준이 높았다고 보고한 견해와 같았다. $\mathrm{Kim}$ 은 구강보건교육을 수강한 학생의 구강보건 태도 및 실천 행동수준이 미수강한 학생보다 높다고 보고하였고, Lee [16]는 
Table 5. Logistic regression analysis of oral health education experience, dental floss use and dental clinic visit

\begin{tabular}{|c|c|c|c|c|}
\hline \multicolumn{2}{|c|}{ Category } & \multirow[t]{2}{*}{ Odds ratio } & \multirow[t]{2}{*}{$\mathbf{9 5} \%$ confidence interval } & \multirow[t]{2}{*}{$p$} \\
\hline \multicolumn{2}{|c|}{ Oral health education } & & & \\
\hline \multirow[t]{3}{*}{ Major } & Non-Health & 1.000 & & \\
\hline & General Health & 0.480 & $0.219-1.052$ & 0.067 \\
\hline & Oral Health & 16.926 & $7.232-39.613$ & $<0.001^{*}$ \\
\hline \multirow[t]{3}{*}{ Grade } & 1 & 1.000 & & \\
\hline & 2 & 1.623 & $0.803-3.278$ & 0.177 \\
\hline & 3 & 4.676 & $1.712-12.770$ & $0.003^{\dagger}$ \\
\hline \multirow[t]{2}{*}{ Sex } & Female & 1.000 & & \\
\hline & Male & 0.632 & $0.334-1.195$ & 0.158 \\
\hline \multicolumn{5}{|c|}{ Use of dental floss } \\
\hline \multirow[t]{3}{*}{ Major } & Non-Health & 1.000 & & \\
\hline & General Health & 1.506 & $0.803-2.827$ & 0.202 \\
\hline & Oral Health & 1.549 & $0.693-3.465$ & 0.286 \\
\hline \multirow[t]{3}{*}{ Grade } & 1 & 1.000 & & \\
\hline & 2 & 2.076 & $1.114-3.766$ & $0.016^{*}$ \\
\hline & 3 & 2.424 & $1.093-5.375$ & $0.029^{*}$ \\
\hline \multirow[t]{2}{*}{ Sex } & Female & 1.000 & & \\
\hline & Male & 0.600 & $0.362-0.993$ & $0.047^{*}$ \\
\hline \multicolumn{5}{|c|}{ Dental clinic visit } \\
\hline \multirow[t]{3}{*}{ Major } & Non-Health & 1.000 & & \\
\hline & General Health & 1.397 & $0.816-2.393$ & 0.223 \\
\hline & Oral Health & 1.163 & $0.575-2.353$ & 0.675 \\
\hline \multirow[t]{3}{*}{ Grade } & 1 & 1.000 & & \\
\hline & 2 & 1.571 & $0.918-2.688$ & 0.099 \\
\hline & 3 & 1.592 & $0.751-3.375$ & 0.225 \\
\hline \multirow[t]{2}{*}{ Sex } & Female & 1.000 & & \\
\hline & Male & 0.489 & $0.311-0.769$ & $0.002^{\dagger}$ \\
\hline
\end{tabular}

${ }^{*} p<0.05,{ }^{\dagger} p<0.01,{ }^{\ddagger} p<0.001$.

구강보건교육 경험이 있는 학생이 구강보건행태가 높게 나왔다 고 보고했다. 본 연구에서 전공계열은 구강보건태도에 영향을 미치고 있었고 $(p<0.05)$, 구강보건교육을 받은 학생에게서 구 강보건태도·실천이 높았음을 확인하였다.

구강관리용품 중 치실사용 여부는 구강보건계열이 높았 고, 구강세정제는 일반보건계열이 높았다 $(p<0.05) .1$ 학년 보다 학년이 높을수록(2학년 odds ratio $[\mathrm{OR}]=2.076,3$ 학년 $\mathrm{OR}=2.424)$, 여학생이(남학생 $\mathrm{OR}=0.600$ ) 치실 사용 빈도가 많 아짐을 확인하였다. 이는 Lee [3], Kim [15], Park과 Moon [17] 등이 치위생학 전공학생에서 높다고 보고한 것과 같았다. Kim [15]은 대학생들이 가장 많이 사용하는 구강관리용품은 구강세 정제였고 남학생의 사용빈도가 높았다고 보고했다. 구강관리용 품은 구강질환의 원인이 되는 치면세균막 관리와 예방에 효과 가 있으므로 개인에 맞는 적절한 구강관리용품의 사용은 구강 질환 예방을 위해 중요하다. 본 연구에서 구강보건교육 경험이 낮은 군에서 구강세정제 사용빈도가 높았으며, 구강보건 교육 경험이 높은 군에서 치실 사용 빈도가 증가함을 확인하였고, 이
는 구강관리용품의 필요성을 제대로 인식하지 못하여 발생한 결 과로 보인다. 이와 관련하여 구강보건교육 시 올바른 구강관리 용품의 사용법과 효과에 대한 내용이 필요할 것으로 생각한다.

칫솔질 방법은 횡마법, 종마법, 치은마사지를 포함한 횡마법, 묘원법, 회전법의 방법을 조사하였으며 계열, 학년, 성별과 무관 하게 회전법을 활용하는 학생이 많았고, 이는 Park [18]의 보고 와 같았다. 하지만 Lee [3]는 치위생학과 학생은 회전법을, 보건 계열과 일반계열에서는 묘원법을 활용하는 학생이 많았다고 보 고하여 차이가 있었다. 이는 구강보건 교육 경험과 관련하여 교 육을 받은 경험이 있으며, 지속적으로 구강건강에 관심을 갖고 있기에 회전법을 활용하는 경우가 높을 수 있기 때문으로 추정 된다[19].

일일 칫솔질 횟수 3번 이상은 구강보건계열, 3학년, 여학생 이 높았는데, Lee [3]와 Park [18]의 보고와 같았으나, Park과 Moon [17]은 남학생(46.7\%)과 여학생(46.9\%) 모두에서 하루 2 번이 가장 높았다고 보고하였다. Jung [20]은 일일 칫솔질 횟수 가 많을수록 흡연율이 낮았음을 확인하여 칫솔질 횟수와 흡연 
이 연관이 있다고 보고하였다. 흡연은 이미 다른 구강질환 관련 유해성이 입증되어 있고, 구강건강 유지를 저해하는 요소로 의 료비 부담도 증가시킨다[9]. 규칙적인 생활과 부모님 배려로 비 교적 양호한 식습관을 가지고 있는 고등학생에 비해, 대학생은 불규칙적인 식습관을 보이며 흡연이나 음주를 접하게 되는 횟 수도 증가하게 된다. 이러한 이유로 Moon 등[21]은 청년기 시 기의 대학생들의 구강건강 관리행태가 이후의 삶의 질에 영향 을 미칠 수 있으므로 올바른 구강건강관리지식과 습관형성은 필수적이라고 지적한다. 구강보건교육 경험이 적었던 군의 흡 연율도 높았던 것이 본 연구에서도 확인되어 대학생의 불규칙 한 생활습관에 맞춘 금연교육과 구강보건교육 프로그램의 개발 이 필요하다고 생각한다.

대학생 교육은 전공수업 위주로 이루어지고 있으므로 일반보 건계열과 비보건계열 학생을 위해 교양과목 혹은 특강 등의 다 양한 형태로 동기부여를 할 수 있는 구강보건교육 프로그램 개 발이 필요하다. 구강보건 계열에서도 $\operatorname{Sim}$ [22]의 연구는 치위생 학 전공학생의 하루 잇솔질 횟수와 정기적인 치과 방문이 학년 에 따라 증가하고, 4학년이 치면세균막 지수가 다른 학년에 비 하여 현저히 낮았다고 보고하였다. 본 연구의 구강보건계열의 구강보건실천도가 학년이 높을수록 실천율이 높아진 것과 일치 한다. 이에 따라 상대적으로 취약한 저학년의 실천도를 높일 수 있도록 교육범위 및 홍보를 강화할 필요가 있을 것이다.

남학생의 흡연율이 높고, 구강보건교육 경험율이 낮은 결과 를 볼 때, 남학생을 대상으로 한 금연교육과 구강보건교육이 추 가적으로 요구된다. 2004년 Park [23]과 2017년 Kang 등[24] 은 군대는 특성상 다양한 소득계층과 지역 등에 따른 구강건강 수준 차이를 해소하고 개인이 주도적으로 책임감을 갖고, 구강 건강습관을 익히는 좋은 기회로 여겨질 수 있다고 설명하고 있 다. 남학생들의 구강보건 인식도와 실천율을 높이기 위한 방안 으로 군인을 대상으로 설계된 구강보건교육 프로그램도 고려해 볼 수 있을 것이다.

본 연구는 제주도내 1 개 대학교를 대상으로 조사되어 일반화 하기에 제한적이며 표준화되지 않은 측정도구를 사용하여 연구 의 한계가 있다. 차후 신뢰도 높은 측정도구의 개발과 함께 대상 자를 확대한 전국 단위의 포괄적인 연구가 필요하다.

\section{CONFLICTS OF INTEREST}

The authors declare that they have no competing interests.

\section{ORCID}

\author{
Ga-Hee Kim \\ https://orcid.org/0000-0001-6472-0371 \\ Hyeung-Keun Park \\ https://orcid.org/0000-0001-7502-5710 \\ Se-Hoon Kahm \\ https://orcid.org/0000-0001-6945-8480 \\ Jae-Man Woo \\ https://orcid.org/0000-0001-7209-186X \\ Chan-Woo Jo \\ https://orcid.org/0000-0003-4777-0080 \\ Sung-Joon Kim \\ https://orcid.org/0000-0003-0603-4036
}

\section{REFERENCES}

1. Public Oral Health Textbook Development Committee. Public oral health. 4th ed. Seoul: KMS; 2016.

2. Ministry of Education. Career statistics of graduates [Internet]. Daegu: Ministry of Education; 2018 [cited 2019 Jun 5]. Available from: https://www.schoolinfo.go.kr/ei/ss/Pneiss_ a02_s0.do.

3. Lee SB. The effect of oral health related factors on oral health knowledge, attitude and practice of some college students [Thesis]. Busan: Dong-eui University; 2018.

4. Korea Centers for Disease Control \& Prevention. 2015 National health and nutrition survey [Internet]. Cheongju: KCDC; 2016 [cited 2016 Dec 21]. Available from: https://knhanes.cdc.go.kr/knhanes/sub04/sub04_03. do? classType $=7$.

5. Korea Centers for Disease Control \& Prevention. 2016 National health and nutrition survey [Internet]. Cheongju: KCDC; 2018 [cited 2018 Jan 4]. Available from: https://knhanes.cdc.go.kr/knhanes/sub04/sub04_03. do? classType $=7$.

6. Korea Centers for Disease Control \& Prevention. 2017 National health and nutrition survey [Internet]. Cheongju: KCDC; 2019 [cited 2019 Jan 11]. Available from: https://knhanes.cdc.go.kr/knhanes/sub04/sub04_03. do? classType $=7$.

7. Lee SM, Ha JE, Kim MJ. A comparative study on the oral health behaviors of health-related and health-unrelated majors in school. J Korea Contents Assoc 2016;16:696702. doi: 10.5392/JKCA.2016.16.02.696.

8. Park CB, Park SY, Jung YE, Lee JH, Kim HJ, Lee MK, Yoon HS. Investigation into the oral health knowledge and oral health behavior of college students: the case of healthrelated majors and non-health related majors. J Korea Soc 
Oral Health Sci 2015;3:41-49.

9. Lee HO, Kim AJ. Analysis of smoking characteristics and oral health practice in health and non-health related majors. J Dent Hyg Sci 2014;14:183-190.

10. Lee MH. An empirical study regarding determinants affect teeth's health of adults in Jeju areas. Korean Acad Dent Hyg 2007;9:89-100.

11. Kim YH. Oral health education on recognition and their prevalence of dental caries comparative analysis of some primary school pupils' in Buckjeju-gun. J Korean Acad Dent Hyg Educ 2002;2:1-17.

12. Kim JA. A study on the perception and practice of oral health of high school students in Jeju island. Journal of the Cheju Tour Coll 2000;6:405-419.

13. Oh HS. A comparative study on for the use of auxiliary oral hygiene devices and tooth brushing between dental hygiene students and non-dental hygiene students. J Den Hyg Sci 2009;9:121-127.

14. Yoon HS, Nam YY, Ryu HA, Kim HJ, Lee MK, Lee JH. A survey on oral health knowledge and oral health perception of university students in some districts. J Korean Soc Oral Health Sci 2013;1:107-115.

15. Kim SJ. A study of oral health recognition and behaviors of college students in Jeonbuk [Thesis]. Iksan: Wonkwang University; 2012.

16. Lee BR. The effect of oral health belief on oral health behaviors in dental hygiene student [Thesis]. Iksan: Wonkwang University; 2015.
17. Park HR, Moon SJ. Survey on the knowledge level of oral health and prevention behaviors of some college and university students. J Korean Soc Dent Hyg 2009;9:485-490.

18. Park SH. Comparison on oral health knowledge, attitude and behavior of college students in Jeollabuk-do Korea [Thesis]. Iksan: Wonkwang University; 2010.

19. Lee SH, Park IS. A study on the use of oral health care devices and the oral hygiene in some colleges. J Korea Acad Industr Coop Soc 2011;12:2629-2635. doi: 10.5762/ KAIS.2011.12.6.2629.

20. Jung TY. Relationship between oral and general health behaviors among adolescents residing in Taean province [Thesis]. Seoul: KyungHee University; 2009.

21. Moon SJ, Kim HN, Ku IY. Research on the smoking conditions of college students and the behavior and awareness of oral hygiene. Int J Cont 2012;12:258-266. doi: 10.5392/ JKCA.2012.12.11.258.

22. Sim SJ. Impact of knowledge provided by dental hygiene education on oral health promotion. Oral Biol Res 2015;39:135-142. doi: 10.21851/obr.39.2.201509.135.

23. Park KO. A study on the needs for oral health education of US Force in Korea and Katusa [Thesis]. Seoul: Yonsei University; 2004.

24. Kang MK, Seo HY, Choi YR. The convergence effect of oral behavior on oral health related quality of soldiers. J Korea Converg Soc 2017;8:151-159. doi: 10.15207/ JKCS.2017.8.9.151. 